\title{
ELECTRONIC FUEL INJECTION TECHNIQUES FOR HYDROGEN POWERED I.C. ENGINES
}

\author{
C. A. MacCarleY* and W. D. Van Vorst
}

\begin{abstract}
Numerous studies have demonstrated the advantages of hydrogen as a fuel for Otto Cycle engines due to high thermal efficiency and low.exhaust pollutant levels. Characteristic of hydrogen engine operation using premixed intake charge formation is a problem of pre-ignition resulting in an intake manifold "backfire". Additional problems include high $\mathrm{NO}_{x}$ production when using certain equivalence ratios and power output degradation due to low fuel energy/volume density.

Techniques for direct and port fuel injection are discussed as means for overcoming these problems. Emphasis is placed on the need for total engine control, integrating control of fuel injection, ignition timing, intake air throttling, and vehicle subsystems within a central electronic unit. An electronically actuated fuel injection valve and a prototype electronic control system are developed. These are applied in port and direct injection system geometries, and evaluated in engine testing. System effectiveness and feasibility are discussed.
\end{abstract}

\section{INTRODUCTION}

THE CASE for hydrogen as an internal combustion engine fuel has been advanced elsewhere $[1,2]$ and need not be reviewed in detail here. Briefly, it offers exhaust emissions free of carbon compound pollutants, and increased thermal efficiency. At the same time, it suffers from erratic intake backfire which makes for rough, and sometimes hazardous engine operation when using certain fuel--air ratios, and decreased power output due to the large hydrogen volume fraction of the fuel-air mixture. The backfire problem alone has proven to be one of the key obstacles to practical utilization of hydrogen engines. The low energy of ignition required to initiate combustion of hydrogen and the wide limits of flammability of mixture ratios are primarily responsible for this situation. With air and hydrogen mixed in the conventional carbureted intake system, numerous unintentional sources of ignition are apparently contacted which serve to promote backfire. Water injection, refined ignition systems, and attempts to eliminate random ignition sources have failed to solve the problem of backfire.

Injection of hydrogen directly to the combustion chamber offers the promise of greatly reducing and conceivably eliminating the problem. Ideally, delaying any contact of hydrogen and air until just prior to ignition is desired, which would make random pre-ignition (with consequent backfire) impossible. While consideration of charge mixing time and constraints dictated by other aspects of the overall system (pressure available for the injection of hydrogen, for example) make such perfect injection impractical, the injection approach still seems worthy of development. In addition to the potential solution of the backfire problem, it offers improved accuracy of control. Timed injection of the fuel should enhance the effectiveness of controlling the engine operation by varying the fuel-air ratio rather than by intake manifold vacuum. Pumping losses of the latter would be minimized and thermal efficiency increased accordingly. Timed injection would permit taking the fullest advantage of the remarkably wide region of stable combustion between the flammability limits of approximately 8.7 and $75 \%$ by volume (29.6\% being the stoichiometric). In terms of the equivalence ratio, $\phi$, the practical range is $0.23-7.34$. The equivalence ratio is defined as the ratio of the actual fuel-air ratio used to the stoichiometric; it is generally used to correlate such variables as ignition energy, flame speed, flammability limits, spark advance, and exhaust gas composition.

Obert [3] classifies fuel injection systems for spark-ignited (SI) engines in three categories:

A. Direct cylinder injection

B. Port injection

(a) Timed

(b) Continuous 
C. Manifold injection or pressure carburetion.

In this work we will focus upon timed injection, either direct to the cylinder or at the intake port just upstream of the intake valve. Continuous injection systems, either at the intake port or as pressurized carburetion will not be considered because they do not allow for separation of the fuel and air intake streams, which is one of the primary objectives of hydrogen fuel injection for suppression of intake manifold backfire.

The value of direct cylinder injection for hydrogen has been recognized for some time, having been attempted in the early work of Erren $[4,5]$ in 1932 . He used a third valve to admit the hydrogen from a pressurized source. More recently, Oehmichen [6], Murrary and Schoeppel [7], Saga and Furuhama [8] and McClean et al. [9] have tested timed high pressure, mechanically controlled direct injection techniques. Swain and Adt have demonstrated a novel "Hydrogen Induction Technique" in which fuel flows through holes in the seat of the intake valve. Their reports based on the performance of a Toyota 1600 powerplant verify the effectiveness of the use of a separate fuel delivery point over premixed charge aspiration in minimization of the ramifications of pre-ignition during the intake stroke [10].

Port injection systems have been in general use on gasoline fueled engines for quite some time. Both mechanically and electronically controlled systems are currently available. Direct cylinder injection of gasoline has been demonstrated on the Mercedes-Benz 300SL, and on power plants produced by Goliath and Borgward. It has been generally concluded that the minor advantages of gasoline direct cylinder injection over port injection are not warranted in view of the requirement that the injection valve survive the combustion chamber environment in the direct injection system [3, p. 405].

Mechanical injection systems have appeared for many years in racing vehicles and in consumer applications. The earliest successful commercial offering of electronic fuel injection appeared in the 1958-59 Chrysler 300 sedan, a Bendix designed system [11]. In 1967, a system produced by Robert Bosch appeared in the Volkswagen Variant model, primarily designed to reduce emissions in the face of 1968 U.S. pollution control regulations. This system offered "computerized" control, and successfully reduced exhaust emissions and improved fuel economy significantly compared to the noninjected model [12]. Systems similar to this now appear in current model vehicles manufactured by Volkswagen-Porsche, Datsun, Volvo, General Motors, Chrysler, Citroen and others [13].

The flexibility of control offered by the electronic system permits features of fuel shut-off during deceleration, precise fuel metering and cylinder distribution, cold start enrichment, compensation for absolute air pressure (altitude compensation), enrichment for acceleration and full load, overspeed cut-off, and protection from flooding. Automated production processes are now available for rapid individual system calibration [14]. The recent popularity of these systems is due to public and governmental demands for improved fuel economy and reduced emissions. It may be inferred from the commercial success of these systems that design sophistication and economics of production favor the electronic injection system over mechanical. With this observation, and the added control problems associated with backfire suppression in hydrogen fueled engines, it appears that an electronic system offers the greatest promise.

With the advent of advanced, low cost digital electronic technology, the implementation of even a very complex control function is often reduced to a problem of appropriate programming of a microprocessor. Hybrid and integrated circuits are finding a rapidly expanding field of application in automotive engine control. Delco division of General Motors offers the MISAR microprocessor based ignition control system on several 1978 model cars [15]. Programmed storaged of an experimentally generated engine parameter map could provide for optimal total engine control -injection, ignition, fuel system and vehicle accessories.

\section{ADVANTAGES AND LIMITATIONS OF HYDROGEN FUEL INJECTION RELATIVE TO CARBURETION}

\section{Backfire-control}

The energy required for ignition of hydrogen-air mixture is significantly lower than that required for other common fuels. Its dependence on $\phi$ is given in Fig. 1. This property is seen to be the root of the pre-ignition problem associated with hydrogen engines. Undesired auto-ignition may occur 


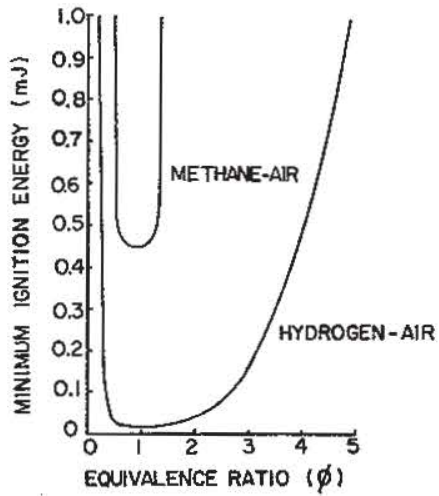

FlG. 1. Minimum ignition energy as a function of $\phi$ for hydrogen-air and methane-air mixtures.

from a number of possible sources. Pre-ignition during the engine intake stroke results in an intake manifold "backfire". In an engine aspirated with a pre-mixed charge, the backfire involves combustion of not only the in-cylinder fuel charge, but the contents of the intake manifold as well. The results of this range from a simple engine misfire to destruction of the carburetion system and fuel system fire. Potential pre-ignition sources include combustion chamber hot spots, residual hot or still burning exhaust products, suspended oil, carbon or dust particles serving as combustion nuclei, and spark plug discharge due to electromagnetic cross induction between plug leads $[16,17,18]$. Additionally, King noted the properties of certain non-catalytic surfaces as conducive to autoignition [19]. Pre-ignition may occur at the porcelain insulator of a spark plug at a lower-temperature than at a cast iron surface of the cylinder head. Many methods of dealing with the backfire tendency have been attempted. Some reduction has been achieved using combustion modifiers, notably water or water vapor. Water induction has been shown to reduce $\mathrm{NO}_{x}$ emission as well [20].

Hydrogen injection greatly reduces the chances of intake stroke pre-ignition occurring, and circumvents the ramifications of a random backfire, should it occur, due to: (a) the ability of the system to initiate fuel delivery at a timing position some time after the beginning of air intake, and (b) the intake manifold contains no combustible fuel-air mixture. In a carbureted engine, valve overlap between the exhaust and intake stroke can bring the incoming fuel-air charge in contact with the residual hot or still burning gases (in very lean mixtures or in isolated areas of an incompletely mixed charge) of the preceding exhaust stroke. This effect becomes pronounced under low rpm, high load conditions where backflow into the intake manifold is tolerated due to a valve timing design trade-off to insure optimum flow under high rpm, peak power conditions. Delayed delivery of hydrogen insures against possible pre-ignition due to this effect. Additionally, a certain "pre-cooling" effect of the air inducted prior to the onset of fuel delivery is realized. This may reduce the effect of surface related pre-ignition sources and provide for a dilution or quench of any residual hot combustion products present in the compression space near TDC. If water induction or injection is employed, it will have an enhanced effect as a pre-cooling medium. Due to the lack of a combustible mixture in the intake manifold, should pre-ignition occur during the intake stroke, its effect will be a partial-charge single cylinder backfire far less consequential than that encountered when the entire charge in the intake manifold ignites in a multi-cylinder carbureted engine.

\section{Quality governing}

An air-hydrogen mixture will successfully ignite and burn over a wide range of composition. At conditions of $17^{\circ} \mathrm{C}, 1 \mathrm{~atm}$, downward flame propagation in a $1.6 \times 30 \mathrm{~cm}$ closed firing end tube will take place between limits of 7.7 and 72.6 molar \% hydrogen [21]. Corresponding equivalence ratios $(\phi)$ are 0.20 and 6.31 
Coward and Jones [22] have presented data on variation of the flammability limits with temperature and pressure. The lower flammability limit, $\phi_{\text {lower, }}$, is somewhat reduced by increasing temperature and rises with increasing pressure to a peak at $20 \mathrm{~atm}$, decreasing at pressures above this. $\phi_{\text {lower }}$ varies between 0.16 and 0.29 in the extremes of the data available $\left(1<p<210 \mathrm{~atm}, 10<T<400^{\circ} \mathrm{C}\right)$. Under conditions encountered at the point of ignition in a typical reciprocating engine, limits of approximately 8.7 and $75 \mathrm{vol} \%$ hydrogen are estimated $(0.23<\phi<7.34)[22,23]$.

This wide range allows the possibility of "quality governing" control in which a powerplant may be controlled by varying the fuel-air ratio rather than intake manifold vacuum. As a constant manifold pressure near atmospheric may now be maintained, engine pumping losses, significant under partial throttle conditions, are reduced. Thermal efficiency under partial load increases.

Quality governing is easily implemented with fuel injection due to the independence of the fuel delivery rate from the air intake rate. This is not the case in carbureted systems; a constant $\phi$ is maintained (theoretically) by the gas mixing carburetor.

The engine idling condition is defined by minimum fuel delivery. In a quality governing scheme, a practical minimum equivalence ratio is established slightly above, but near the $\phi=0.23$ lean flammability limit. De Boer et al. [18] recommend a minimum practical limit of $\phi=0.30$. Experimental engine performance has shown the need for a certain amount of manifold vacuum to establish an acceptable idle. As a quality governed engine incurs minimal pumping losses, only frictional,

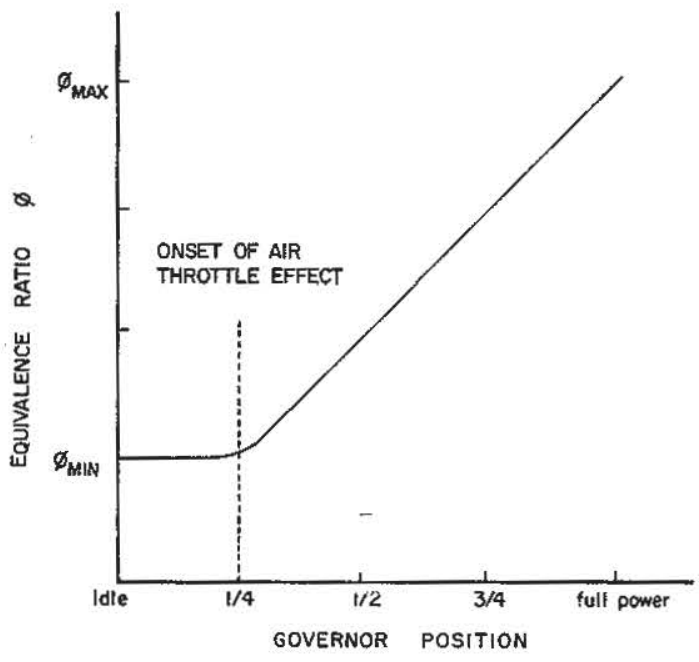

Fig. 2. Equivalence ratio vs pedal position for the AMC-232 system.

compression and engine accessory loads establish the idle condition. Operation with very lean values presents problems due to incomplete combustion and long combustion times. Fuel energy is wasted due to incomplete combustion, and a potential backfire condition is created due to residual combustion at time of intake. Reduction of the fuel-air charge energy content below the equivalence ratio of minimum acceptable combustion requires reduction of the air pressure in addition to the fuel fraction, or the use of a charge dilutant such as recirculated exhaust gas. Air pressure reduction is most easily attained and implies the need for some degree of throttling. This throttling would effectively establish a constant equivalence ratio below a certain governor position, as plotted in Fig. 2. The manifold vacuum created, as a pumping loss factor, also assists in maintaining a stable idle speed. A pure quality governed engine behaves much like a two cycle engine in its very gradual deceleration when unloaded.

Maximum fuel delivery would optimally be that rate which establishes a $\phi=1.0$ intake charge equivalence ratio. Maximum power output is achieved in this case. Consideration of $\mathrm{NO}_{x}$ emissions 
may dictate a different $\phi_{\max }$ or may suggest an incremental type of fuel delivery near the "full throttle" condition as will be described in the following section.

\section{Control of nitrogen oxides emissions}

$\mathrm{NO}_{x}$ formation in the hydrogen-air engine is fundamentally dependent on factors of reaction temperature and residence time. These are in turn functions of equivalence ratio, compression ratio, and cylinder geometry. According to de Boer et al. [18], for mixtures leaner than $\phi=0.8$ the NO reaction is limited by thermal quenching during the formation processes, while for mixtures richer than this, the net NO emissions are determined by quenching of NO decomposition reactions during the expansion stroke. The data of McLean et al. [9] relating $\mathrm{NO}_{x}$ emission in $\mathrm{gm} / \mathrm{h}$.p.-hr to $\phi$ is depicted in Fig. 3. Of significance in this discussion is the existence of a high $\mathrm{NO}_{x}$ region between $\phi=0.65$ and $\phi=0.95$, with a peak at $\phi=0.8$. Operation of an engine within this range of equivalence ratios results in high $\mathrm{NO}_{x}$ emissions relative to power output, a considerable blemish to the otherwise clean exhaust, primarily water vapor and nitrogen.

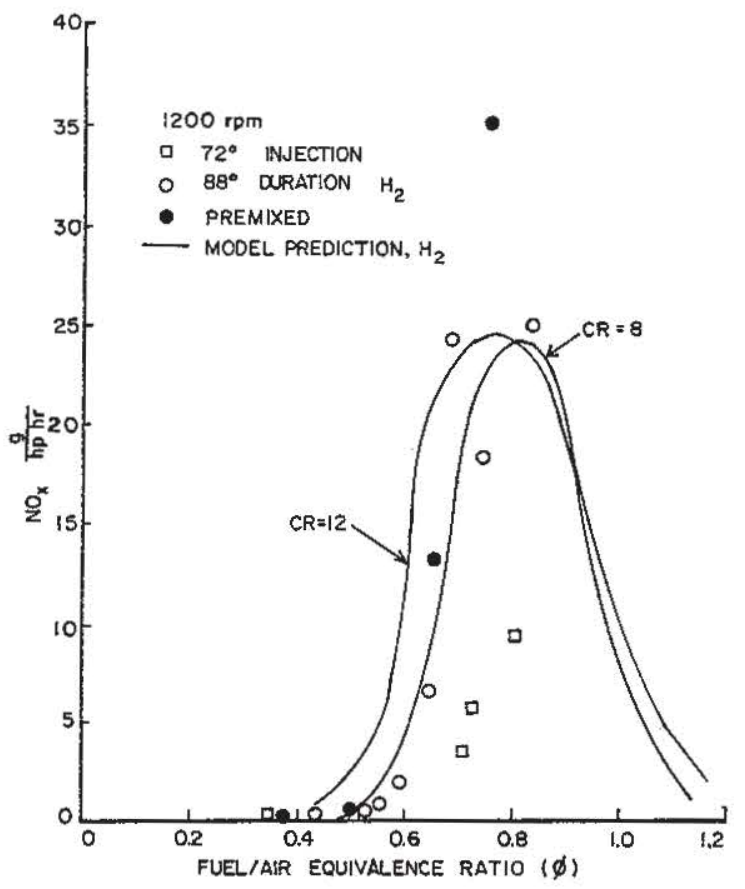

FIG. 3. Model predictions for $\mathrm{NO}_{x}$ production (data of McLean et al.) [9].

Electronic injection control allows a unique possibility for avoiding high $\mathrm{NO}_{x}$ production without limiting $\phi$ to below 0.65 . For full power, it is desirable to have available a mixture of $\phi=1.0$. For a multi-cylinder engine it would be possible to "jump through" the region of high $\mathrm{NO}_{x}$ emission $(0.65<\phi<0.95)$ one cylinder at a time, or in pairs of opposing cylinders, as the governor is advanced through positions corresponding from $2 / 3$ power to full power. Thus the entire condition of high $\mathrm{NO}_{x}$ production is avoided with a tolerable degree of acceleration "surge" incurred near full power.

\section{Ignition timing control}

Combustion flame front velocity for the hydrogen-air mixture is a function of equivalence ratio $(\phi)$. Figure 4 correlates the data of Breton [24] and Wendlandt [25] on laminar and unstable flame 


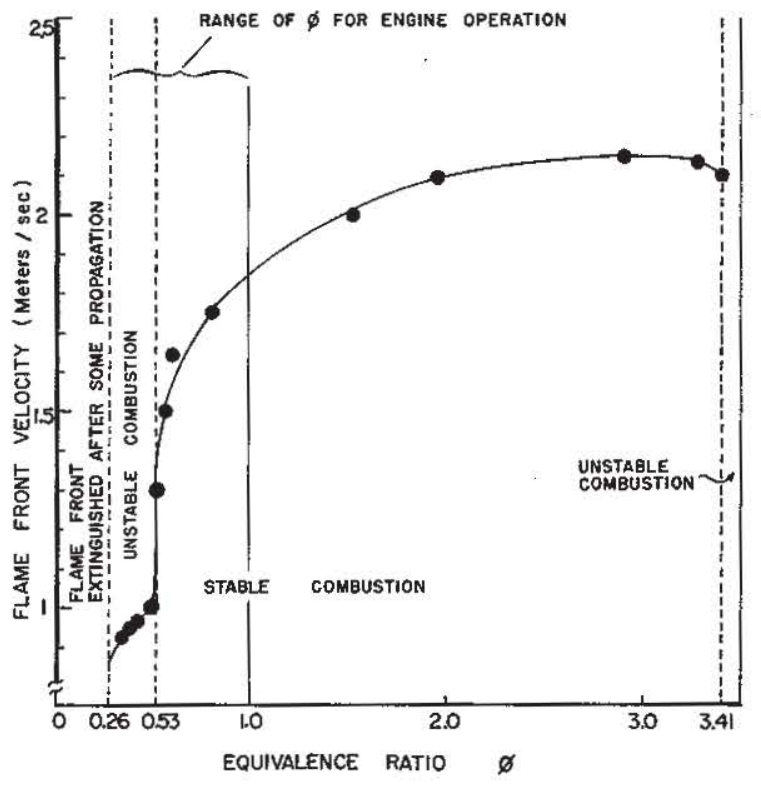

FIG. 4. Flame front velocity of $\mathrm{H}_{2}$-air mixtures $(P=1 \mathrm{~atm}$, ignition in closed end glass tube. Data composite of works by Breton [24] and Wendlandt [25], from [26]).

front propagation, respectively. Experiments were conducted using downward flame propagation in a glass tube at atmospheric pressure in both cases. An abrupt transition occurs at $\phi=0.53$ as flame propagation changes from laminar for $\phi>0.53$ to unstable for $\phi<0.53$. Unstable flame propagation is characterized by decreasing flame front velocity with travel distance. For $\phi<0.26$ the flame front self-extinguish after a certain propagation distance which is variable with charge consistency and types of ignition source. For equivalence ratios approaching the lower limit at $\phi=0.20$, combustion is often incomplete, the degree of completion effected by combustion vessel geometry and charge consistency [22]. An upper regime of unstable flame front propagation occurs for $\phi>3.41$ [26].

Combustion conditions in a reciprocating S.I. engine are quite different from these experimental conditions. Indeed, flame speed can be increased many times by turbulence, as is the case in the confined reaction in the engine combustion chamber [3, p. 27]. Obert concludes that over a large portion of the combustion period, the combustion of any small element of mixture occurs at essentially constant pressure even though the pressure throughout the chamber is continually increasing $[3$, p. 100]. From this point of view, it appears reasonable to infer that flame velocities measured in a constant pressure apparatus will have some validity in a confined reaction.

It may be concluded from the minor variation in flammability limits with temperature and pressure, that if the flame velocity transition occurs under engine combustion conditions, it is likely to occur at a value close to that observed in the laboratory. Experimental data on engine performance seem to verify this, as an abrupt change in ignition timing is required with variation of $\phi$ from 0.4 to 0.6 . The data of Finegold and Van Vorst [1] are shown in Fig. 5. For one case represented, the timing position must be advanced from $60^{\circ}$ BTDC for $\phi=0.4$ to $20^{\circ}$ BTDC for $\phi=0.6$, with timing at TDC for $\phi=1.0$.

The increase in the time required for complete combustion with $\phi$ below the transition value creates a need for greatly advanced ignition timing. Application of quality governing requires the use of low $\phi$ mixtures under light loads and engine idling conditions. Long combustion durations and the onset of incomplete combustion determine a practical lower limit on usable equivalence ratio. The rapid flame velocities encountered with rich mixtures ( $\phi$ approaching 1.0) require ignition timing positions at or after TDC to yield satisfactory cylinder pressure distribution over the combustion stroke. 


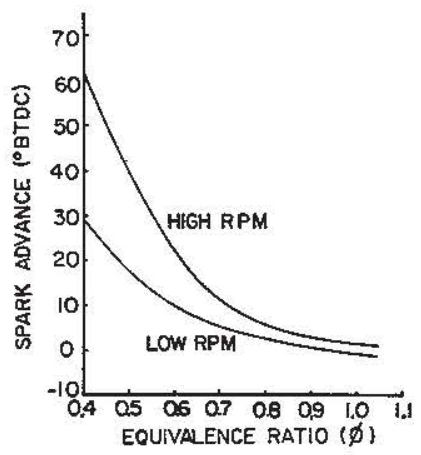

Fig. 5. Optimized ignition timing for a hydrogen engine (from [2]).

Optimum ignition timing is a function of both the fuel-air ratio and the engine speed. For a specific engine, this may not be a simple function that can be readily approximated by a mechanical linkage. Integration of ignition control with injection control provides a straightforward means of maintaining the correct relationship. The desired ignition timing function can be implemented electronically by a central engine control computer, responsible for both injection and ignition system control.

\section{Additional features possible with electronically controlled hydrogen injection}

Deceleration fuel cut-off. As an efficiency improving feature, and to avoid the problem of residual combustion on deceleration due to low combustion speeds at low $\phi$ values, but high engine speeds, it is desired that fuel flow be withheld during deceleration transients. A condition of engine rpm greater than the idle value while the governor is in idle position (foot off the pedal) is identified by the electronics as a deceleration condition, and fuel flow is withheld until the idle speed is attained.

Engine overspeed protection. Fuel delivery may be reduced if engine speed exceeds a predetermined value.

Fuel supply control. Master fuel valve shut off is desirable in conditions of engine stall, on-board fire, or vehicle rollover. Detection of a minimum acceptable engine speed, with over-ride during starting, identifies the engine stall condition. Fire or rollover require suitable sensors.

Interactive control of a cryogenic, metal hydride, or chemical hydride fuel storage system. A heating cycle is used for gas withdrawal from a liquid hydrogen vessel. This can be made to respond to engine fuel demands either via line pressure data or in a linear control scheme in which heat admitted to the $\mathrm{LH}_{2}$ loop is made to track fuel mass flow requirements. A similar control scheme is used in metal hydride storage in which engine exhaust or coolant heat is used for hydrogen release from a hydride bed. In a chemical hydride storage system such as the sodium borohydride system, parameters of reaction temperature, solution $\mathrm{pH}$, and catalytic surface area contact are available for control of the hydrogen release reaction [27]. An optimized control scheme for hydrogen supply in response to engine demand may be implemented through the engine control electronics.

Interactive control of a water injection system, if applied. Water delivery may be tailored to the requirements of the powerplant for backfire suppression or $\mathrm{NO}_{x}$ reduction only as actually required. Practically, water injection might be applied so as to track hydrogen flow proportionally or be applied only under conditions of high $\phi$ and high load.

\section{Special considerations for direct cylinder injection}

Direct injection permits fuel delivery after the closure of the intake valve, during the compression stroke. Due to the pseudo-exponential nature of the (ideally) isentropic compression, only a moderate 


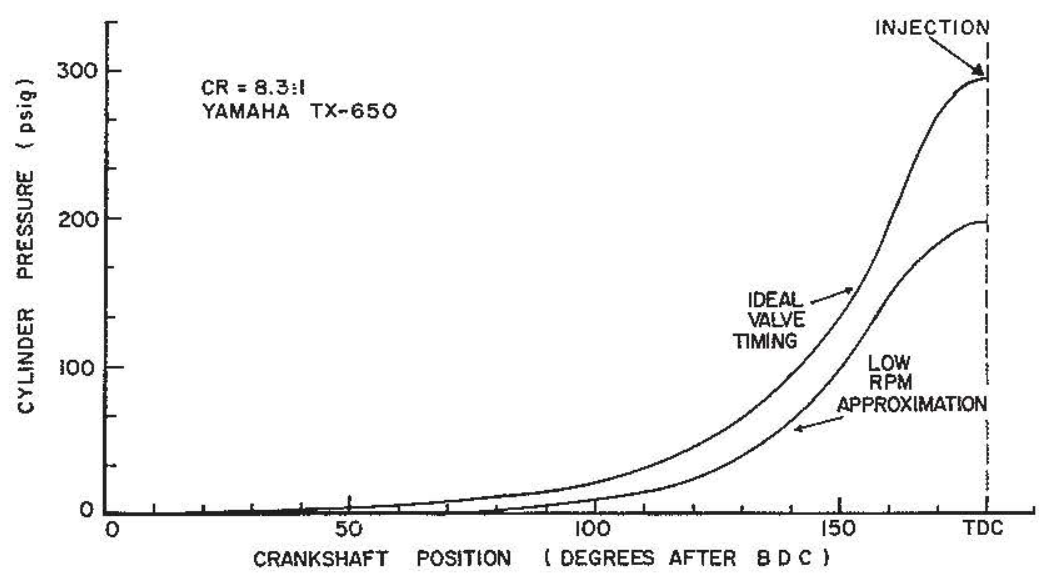

Fig. 6. Calculated cylinder pressure vs crankshaft position based on isentropic compression approximation.

pressure ( $30 \mathrm{psig}$ ) is required for injection as late as $90^{\circ}$ after bottom dead center. Figure 6 illustrates an ideal $180^{\circ}$ compression stroke. Also illustrated is a condition of no pressurization until the intake valve is completely closed as an approximation for intake flow at low rpm.

Under stoichiometric conditions, $29.6 \%$ volume of the fuel-air charge is occupied by hydrogen. Comparatively, $2 \%$ volume of a gasoline-air mixture is assigned to gasoline. Thus a power output limitation is imposed on hydrogen engines aspirated at atmospheric pressure, approximately $15 \%$ less than equivalent gasoline performance [9]. This is termed a form of volumetric efficiency loss. Methods of supercharging or direct cylinder injection allow recovery of this loss by charge pressurization, either during the intake stroke in the first case or during the compression stroke in the latter. If the duration of injection occurs entirely in the compression stroke, it is possible to recover completely the volumetric efficiency loss. A power output improvement of $42 \%$ (in the theoretical limit) is possible. Partial overlap of injection into the intake stroke proportionally reduces this advantage.

A problem exists if injection takes place in the vicinity of BDC due to late closure of the intake valve. It is possible that backflow of hydrogen out of the intake valve may occur in the period between BDC and the point where the intake valve is fully shut. This can only occur to a significant degree at lower engine speeds (compared to the rpm of maximum power) due to gas inertia in the intake manifold. The consequence of this is a small residual amount of hydrogen upstream of the intake valve.

Saga and Furuhama and others [18] have noted problems with adequate fuel-air mixing for injection timing positions late in the compression stroke. The heterogeneous fuel-air charge resulting after late injection can cause problems of erratic ignition and incomplete combustion. Stratified charge formation may be valuable for very low overall mixtures as a means of achieving complete combustion. It is undesirable for mixtures approaching $\phi=1.0$. Optimum injector discharge direction and in-cylinder turbulence are required for higher pressure injection with timing closer to TDC.

Further evidence of hydrogen-air mixing difficulties has been contributed by Wooley [20] and others who have reported variations in cylinder to cylinder fuel-air ratios using pre-mixed charge formation. Using a multicylinder engine powered by propane, $\mathrm{Yu}$ [28] noted significant variation in the mixture ratio between cylinders; only with induction through a manifold consisting of a five-foot hose, swirl chamber, and venturi could this be reduced to an acceptable limit. While the wide flammability limits of hydrogen are tolerant of these variations in premixed charge induction, systems employing in-cylinder charge formation must be designed to insure adequate mixing in order to avoid heterogeneous charge formation and associated problems of poor ignition and incomplete combustion. Otherwise, low thermal efficiency and erratic $\mathrm{NO}_{x}$ formation may result.

The low ignition energy of hydrogen facilitates successful spark ignition. Conventional spark plugs are usually gapped at a narrow setting, taking advantage of the low minimum quenching distance of hydrogen, approximately $0.6 \mathrm{~mm}$ at $\phi=1.0$. However, unsuccessful ignition has been 
observed in conditions of heterogeneous fuel-air charge composition. It is hypothesized that false ignition occurs due to the presence of local fuel-air mixtures in the vicinity of the igniter which are beyond the flammability limits, either too lean or too rich. Thus, gas ionization may occur without ignition.

Demands on the injection valve

An electronically actuated valve (injector) capable of very fast reaction times and high flow rates is required. Time allowed for injection decreases with increasing rpm or decreasing radial duration of the injection cycle. Thus, for a high speed engine using a narrow radial duration, severe speed and flow requirements are placed on the injector.

For direct injection systems, it is additionally required that the injector be capable of blocking and withstanding the pressure and temperature of combustion. Adiabatic heating alone imposes severe materials requirements.

\section{DESIRED FEATURES OF A HYDROGEN ENGINE CONTROL SYSTEM}

(1) Determination of an injector "on" pulse duration and timing position. Available mechanisms for governing the engine are the injection pulse duration, pressure to the injection valves, and throttle plate position (manifold vacuum control). Pulse duration is determined as a function of:

Throttle position

Fuel pressure and temperature at injector

Manifold air pressure and temperature

Engine coolant temperature

Engine speed.

As will be discussed later, it is desirable to time the injection cycle so that it always ends at a constant radial position. For direct injection, cycle termination at $90^{\circ} \mathrm{BTDC}$ in the compression stroke is optimum (see Fig. 7). This requires generation of a cycle initiation position based upon instantaneous rpm and pulse duration, such that the required injection pulse duration is fitted into the allowed radial duration.
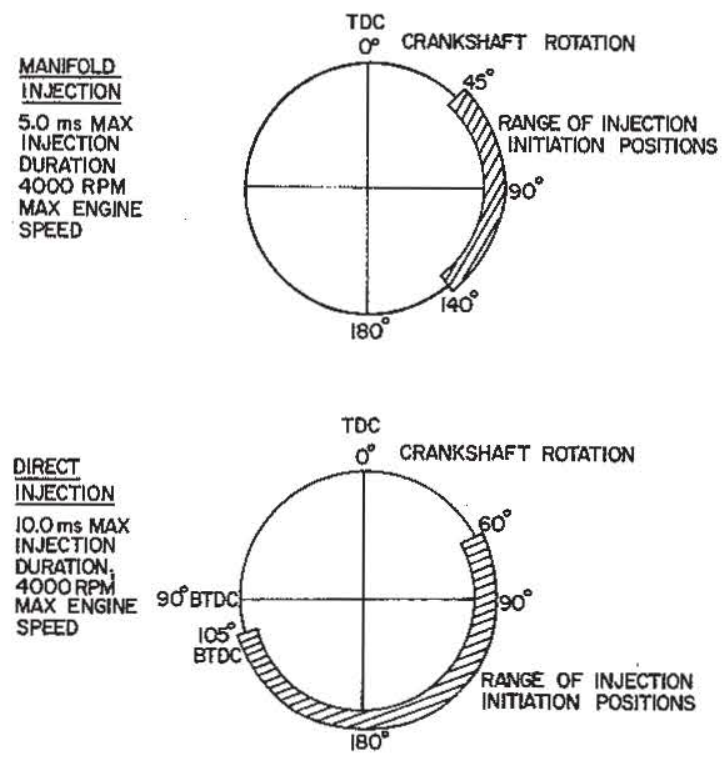

FIG. 7. Injection timing position range for manifold or direct injection, AMC 232 C.I.D. powerplant. 
(2) Dynamic ignition timing determination using instantaneous engine speed and fuel-air ratio information.

(3) "Stepped" fuel delivery to avoid $\mathrm{NO}_{x}$ emissions (as described earlier).

(4) Fuel cutoff on vehicle deceleration or coasting.

(5) Control of a water injection system, if required.

(6) Fuel cutoff in the event of engine stall, on-board fire, or vehicle rollover.

(7) Dynamic control of the fuel storage and delivery system cryogenic, metal hydride, chemical hydride, alcohol or hydrocarbon decomposition, etc.

\section{DEVELOPMENT OF AN EXPERIMENTAL SYSTEM}

As a basis for evaluation, an experimental system which may be configured for either port or direct injection was developed and tested. Additionally, comparative data were taken using carbureted aspiration and on baseline engine performance with gasoline.

Experimental work was based on system installations on a two cylinder, $653 \mathrm{~cm}^{3}$ displacement, air-cooled test engine (1974 Yamaha TX-650). Characteristic of this power-plant is a slightly oversquare bore/stroke $(75 \times 74 \mathrm{~mm}), 8.7-1$ compression ratio, and a valve geometry and timing designed for high speed operation (7500 rpm maximum engine speed).

This work was directed towards the development of an optimized system for use in a prototype mail delivery vehicle for the U.S. Postal Service. The stock 232 C.I.D. powerplant of a 1974 AMC Jeep is to be modified for hydrogen operation in conjunction with a cryogenic fuel storage system. Gaseous hydrogen available to the engine may vary widely in temperature depending on vehicle operating conditions. The injection system must be designed to accommodate fuel over a temperature range of $-50^{\circ} \mathrm{C}$ to $+50^{\circ} \mathrm{C}$, and a pressure range of 40 to $100 \mathrm{psig}$. Final design requirements for the injection system are defined to be compatible with this vehicle package.

Basic components of the injection system for this vehicle, which may be configured for either port or direct injection, are shown in Fig. 8. A block diagram of the injection control electronics is shown in Fig. 9. A schematic of the inter-module wiring of the control computer is shown in Fig. 10. Details of the electronics, injection valve development and experimental apparatus have been given by MacCarley [29]. This paper presents only a system overview.

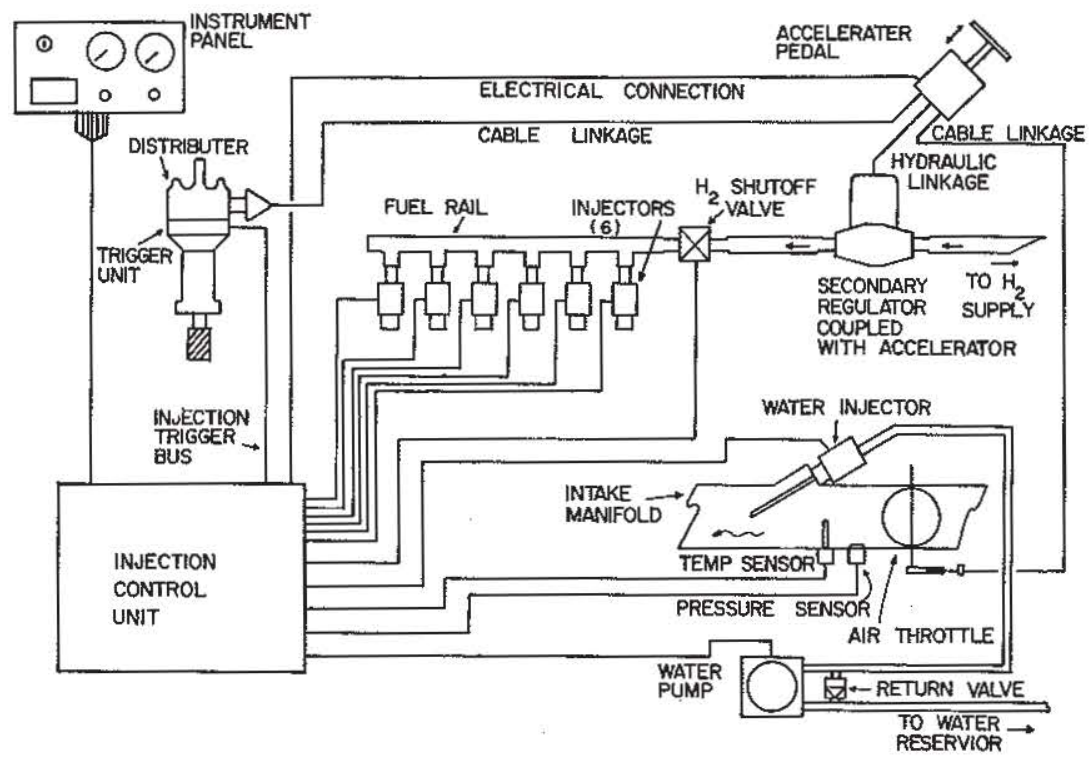

FIG. 8. General layout of electronic hydrogen injection system. 


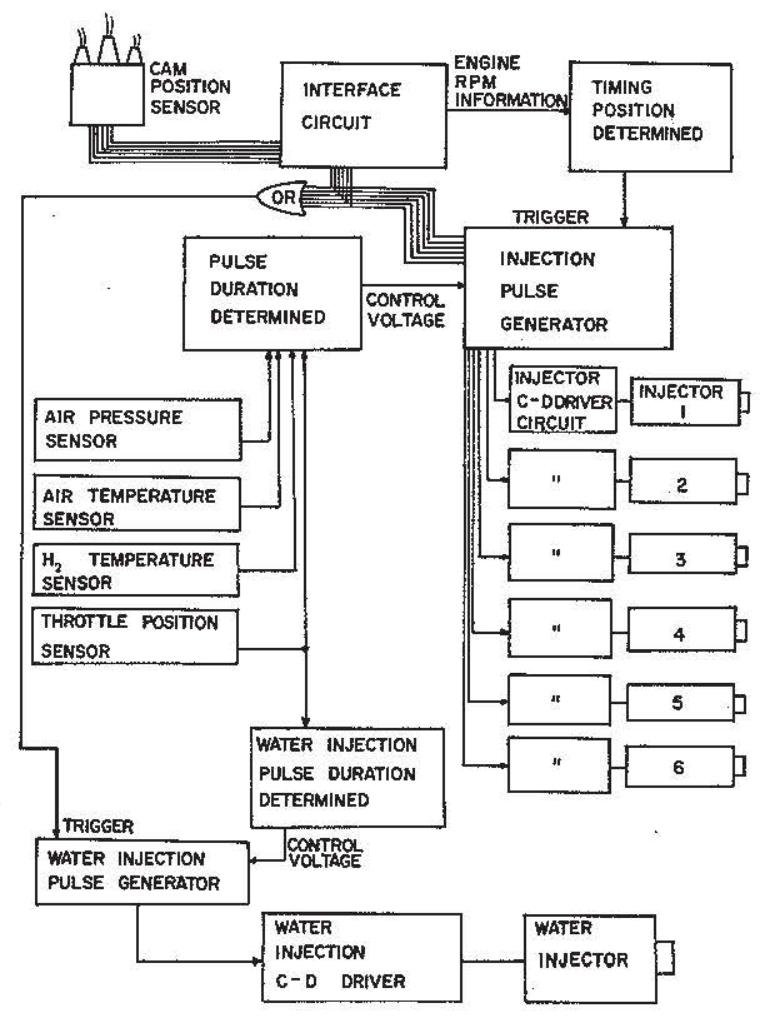

FIG. 9. Block diagram of injection electronics.

Development of a suitable high speed electronically actuated injection valve (or injector) has proven to be a significant obstacle in system implementation. Indeed, certain design limitations of either the port or direct injection system are dictated by the actuation speed and flow capabilities of the injectors.

Three properties are of prime importance in characterizing injector performance:

The steady state flow coefficient, $C_{v}$

The time required for valve opening, $t_{\text {open }}$

The time required for valve closing, $t_{\text {close }}$

$C_{v}$ is an indicator of expected volumetric flow through the valve under steady state conditions for a specific differential pressure, given the upstream pressure and temperature. It is defined by the Fluid Controls Institute (USA) as:

$$
C_{v}=Q \frac{\sqrt{S G \times T}}{13.61 \times P_{1}}, \text { valid for } P_{1}>2 P_{2},
$$

where $Q=$ Flow rate in cubic feet per minute at 1 atm and $70^{\circ} \mathrm{F}$ (SCFM)

$S G=$ Specific gravity of the gas relative to air (both at the standard condition of $1 \mathrm{~atm}$ and $70^{\circ} \mathrm{F}$ )

$T=$ Flowing gas temperature in ${ }^{\circ} \mathrm{R}\left({ }^{\circ} \mathrm{F}+460\right)$

$P_{1}=$ The inlet absolute pressure, psia

$P_{2}=$ The outlet absolute pressure, psia.

The valve actuation times, $t_{\mathrm{open}}$ and $t_{\text {close }}$ are indicators of the ideality of the valve's transient response, zero being the ideal. Conventional solenoid valves are available with $C_{v}$ values compatible with the 


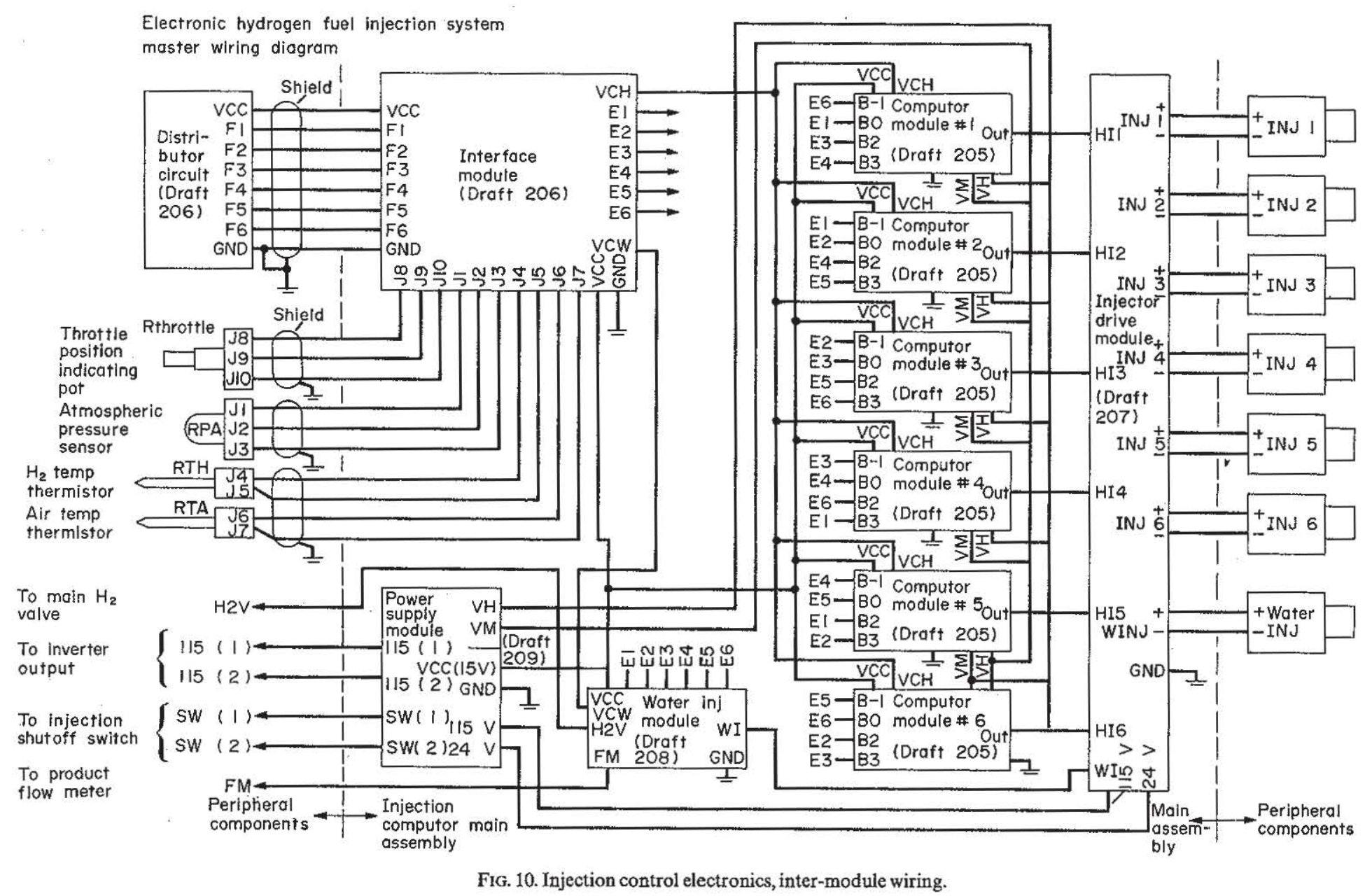


injector design requirements, but actuation times for even the fastest control valves are far too slow to be usable, being typically $100 \mathrm{~ms}$. An electronic fuel injector developed by Robert Bosch $\mathrm{GmbH}$ (Germany) for gasoline systems was tested for flow characteristics using hydrogen. Using a $12 \mathrm{~V}$ pulse actuation signal, an upstream pressure of 75 psig and atmospheric pressure downstream, this valve opened completely in $1.5 \mathrm{~ms}$ and closed in $2.0 \mathrm{~ms}$. These times are acceptable for gasoline injection applications using typical maximum actuation pulse durations of $8.0 \mathrm{~ms}$. $C_{v}$ for this valve, even when modified for improved flow by removal of the metering tip and internal filter, was far too low to be usable with hydrogen $\left(C_{v}=0.011\right)$. Lynch [3] evaluated this injector with similar results. It was determined experimentally that for a $3.75 \mathrm{~ms}$ pulse duration and equal opening and closing times, a circular orifice of $0.178 \mathrm{~cm}^{2}$ cross-sectional area was capable of flowing $200 \mathrm{~cm}^{3} /$ injection cycle (measured at atmospheric pressure) using an upstream pressure of $30 \mathrm{psig}$. This is an acceptable flow rate for injection application to the AMC 232 engine which has a displaced cylinder volume of $634 \mathrm{~cm}^{3}$ and requires $190 \mathrm{~cm}^{3}$ hydrogen delivery for a stoichiometric fuel-air ratio. Fuel delivery required for the TX-650 is $98 \mathrm{~cm}^{3}$ for $\phi=1$, approximately half of the AMC 232 requirements. Fuel requirements for the TX-650 are given by.

$$
\begin{aligned}
& y=\frac{137 \phi}{1+(\phi / 2.38)} \mathrm{cm}^{3} / \text { injection } \\
& \left.y=\text { hydrogen volume (at } 68^{\circ} \mathrm{F}, 1 \mathrm{~atm}\right) .
\end{aligned}
$$

It was recognized that a significant portion of the delay time for valve opening or closing is due to the rise and fall of the magnetic field in the electromagnetic actuator. High speed actuation was found to depend on:

Reduction of the coil inductance,

Reduction of coil resistance for high current operation,

Concentration of field flux at gap between actuator slug and magnet core,

High magnetic permeability of core, field containment shroud, and slug

Light weight moving parts to minimize inertial delays.

However, there are practical restraints on supply current and acceptable injector heat dissipation. Additionally, several parameters are contradictory, i.e. low inductance demands low core permeability, thus lower magnetic field concentration.

Subsequent design optimization resulted in the fabrication and testing of several prototypes, categorized generally as Type I and Type II.

Fastest actuation times were achieved with low inductance coils at the sacrifice of applied force. Thus, maximum orifice size and inlet pressure were limited and flow rate was reduced. Conversely, higher flow rate was achieved with sacrified actuation speed. Concurrently, a modified version of a low inductance prototype was tested for use as a water injector, to be applied in an integrated water injection-hydrogen injection system. Both flow rate and actuation times using water were more than adequate for this application. Using a $5.0 \mathrm{~ms}$ pulse duration and injector actuation with every cylinder firing, a continuous water flow condition would be reached at the $4000 \mathrm{rpm}$ maximum speed of the 6 cylinder engine using a single common water injector to feed all cylinders. Thus, almost linear tracking of hydrogen mass flow may be achieved over the entire range of engine speed and fuel flow. Modifications included provisions for corrosion immunity of internal injector parts.

A two stage valve concept was developed utilizing the principle of fluid amplification (see Fig. 11). A small flow rate, high speed electromagnetic injector is used for primary fluid flow which actuates a larger valve surface providing high flow rate. The valve geometry is such that it is capable of withstanding very high reverse pressure differentials without significant backflow. This feature makes it compatible with direct injection requirements wherein the injection valve must be capable of blocking combustion peak pressures. Tests on a prototype of this valve (designated Fluidamp injector) demonstrated more than adequate hydrogen flow rate. Actuation time, however, is sacrificed due to the two stage valve geometry. Valve closure requires both primary valve closure and depressurization of the displaced volume between the poppet face and the nose of the primary injector.

The long valve closure time of the Fluidamp injector need not present a problem in direct injection applications if the injection cycle is timed to terminate late in the compression stroke of the engine. Thus, cylinder compression may be used to effectively terminate hydrogen injection at the point where the cylinder pressure exceeds the secondary injection pressure. Dynamic injection timing as 

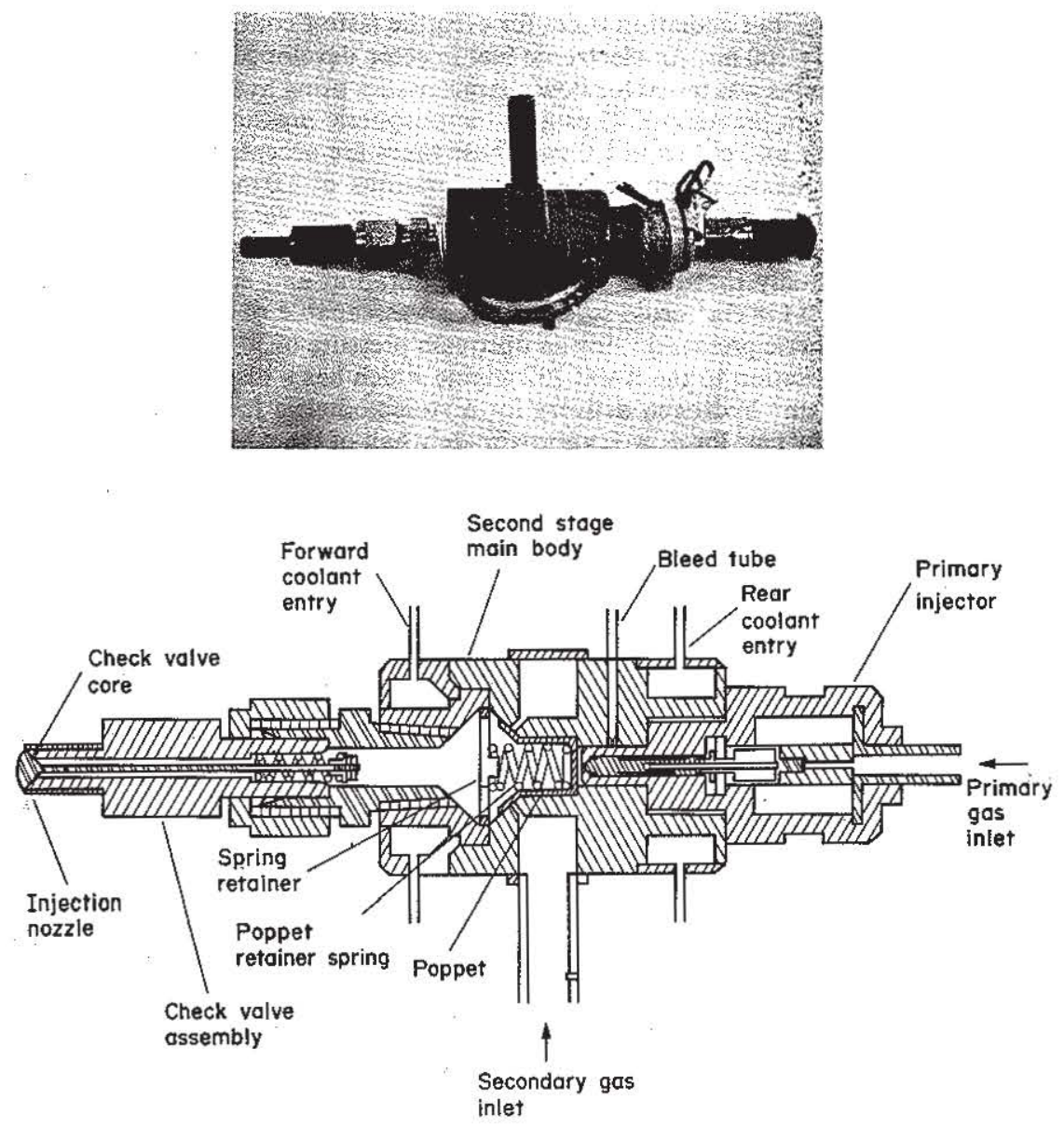

FIG. 11. Fluidamp injector.

a function of rpm and pulse duration such that this termination occurs at the correct piston position is a feature of the control electronics. Essentially, injection initiation is delayed for a period of time determined by the engine speed. The time delay function with rpm is shown in Fig. 12.

Injector flow characteristics were evaluated experimentally for all prototypes. Delivery volume was measured by displacement of a graduated water column. Dynamic flow response was determined by recording instantaneous pressure in an accumulator which supplied hydrogen to the injector under test. Injection flow depressurizes the accumulator. Pressure traces were generated by oscilloscope displays of signals from a piezo-electric fast-response pressure transducer. Flow rate is inferred by graphical differentiation of oscilloscope photographs. In this case,

$$
Q \sim \frac{-\mathrm{d} P}{\mathrm{~d} t}
$$

where $Q=$ instantaneous flow rate and $P=$ instantaneous pressure in the accumulator. Pressure drops in the accumulator were small over each injection cycle, thus final accumulator pressure deviated only slightly $(\Delta P<3$ psi) from reported pressure data points. Summary data on all injectors are outlined in Table 1.

Increased valve actuation speed was also achieved using purely electronic techniques. Magnetic 


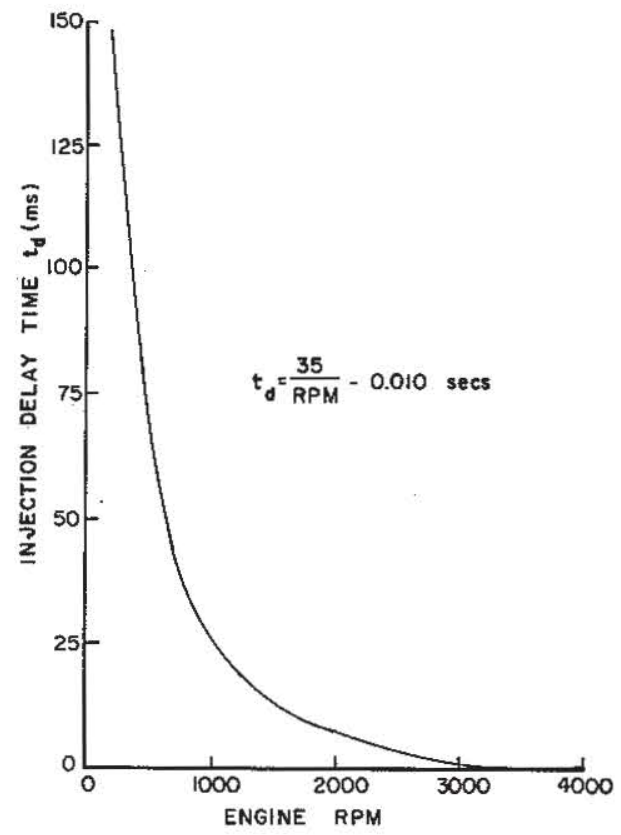

FIG. 12. Injection time delay function for direct injection applied AMC 232 CID powerplant.

field intensity is related to coil current in simple electromagnets by the expression:

$$
|H| \sim N I
$$

(for core materials below the saturation point), where $|H|=$ magnitude of magnetic field, $N=$ number of turns in the coil, and $I=$ current. However, coil inductance, $L$, increases with $N^{2}$. The coil may be electrically modeled as depicted in scheme 1 .

TABLE 1. Hydrogen injection valve comparative data

\begin{tabular}{|c|c|c|c|c|c|c|}
\hline Valve & $\overbrace{\text { opes }}$ & $\underbrace{t}_{\begin{array}{r}t_{\text {elose }} \\
(\mathrm{ms})\end{array}}$ & $C_{v}$ & $\begin{array}{l}\text { Maximum } \\
\text { usable } \Delta P \\
\text { (psig) }\end{array}$ & $\begin{array}{l}\text { Minimum usable } \\
\text { pulse duration } \\
\text { (ms) }\end{array}$ & $\begin{array}{c}\text { Volume delivery, } \\
5 \text { ms pulse at } 30 \text { psig } \mathrm{cm}^{3} \text {, } \\
\text { (Room } T \text { and } P \text { ) }\end{array}$ \\
\hline Solenoid valve (fluid logic type) & 100 & 25 & $\sim 1.5$ & $\sim 150$ & - & - \\
\hline $\begin{array}{l}\text { Bosch petrol injector flowing } \\
\text { hydrogen, }(\Delta P=75 \text { psig })\end{array}$ & 1.5 & 2.0 & 0.011 & 95 & 1.5 & 2.6 \\
\hline Type I hydrogen injector & 2.0 & 2.0 & 0.280 & 45 & 2.0 & 70 \\
\hline Type II hydrogen injector & 1.0 & 1.5 & 0.466 & 50 & 1.0 & 110 \\
\hline $\begin{array}{l}\text { Type II water injector (Hydrogen } \\
\text { flow) }\end{array}$ & 0.5 & 0.8 & 0.148 & 75 & 0.5 & 35 \\
\hline $\begin{array}{l}\text { Fluidamp hydrogen injector (Stock } \\
\text { electronics) }\end{array}$ & 3.0 & 5.0 & 1.02 & $35+$ & 1.0 & 380 \\
\hline $\begin{array}{l}\text { Fluidamp hydrogen injector (CD } \\
\text { electronics) }\end{array}$ & 1.5 & 3.0 & 1.02 & $35 \dagger$ & 0.3 & 240 \\
\hline
\end{tabular}

$\dagger$ Primary pressure $=60$ psig; can be increased by use of higher primary pressure. 
Scheme 1.

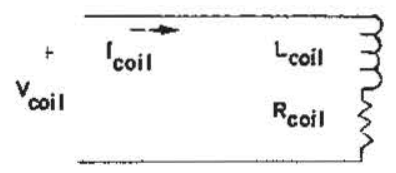

Presented with a voltage step function, coil current will rise according to the expression:

$$
I=\frac{V}{R_{\text {coil }}}\left[1-\mathrm{e}^{-t\left(R_{\text {co } H} / L_{\text {cot } t}\right)}\right]
$$

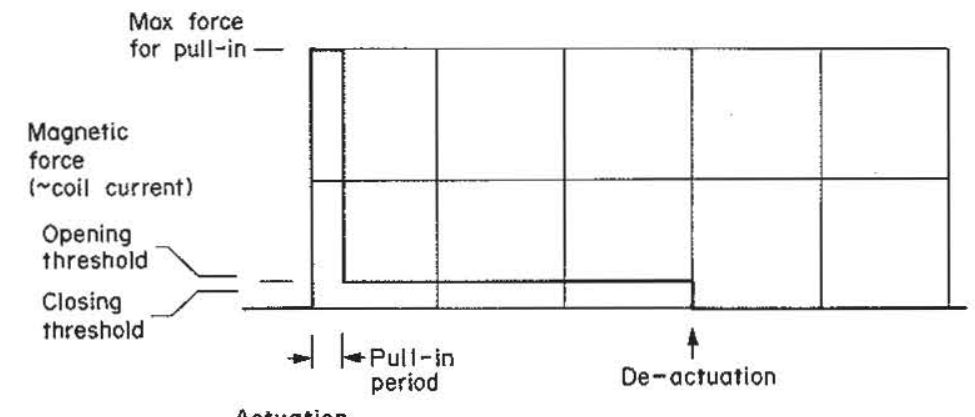

(a)

Ideal magnetic force function

Coil Actuotion

current, A
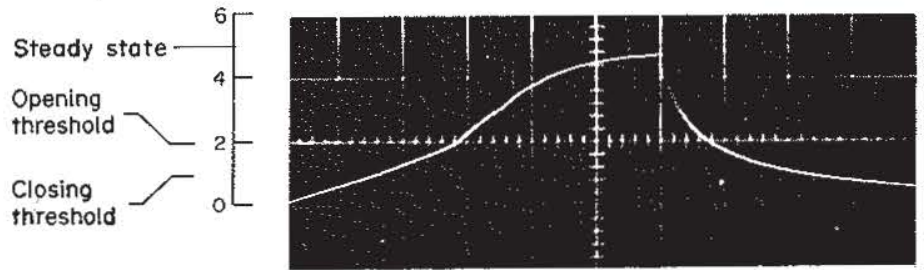

(b)

Coil current

response

using

voltage

step function

drive

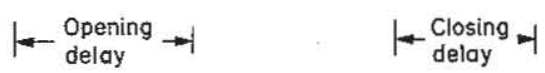

Coil

current,
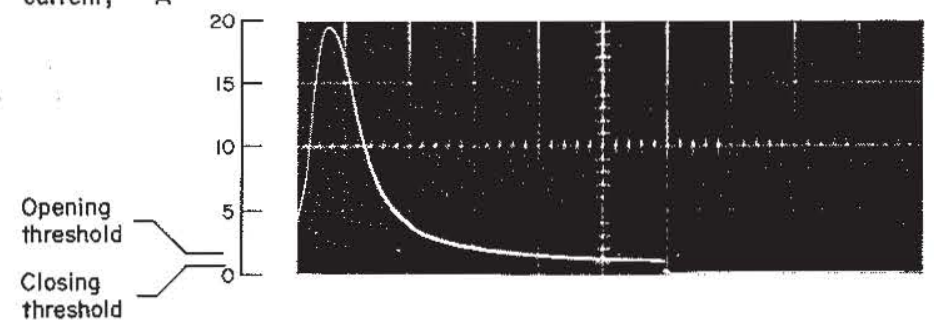

(c)

Coil current

response

using $C-D$

drive circuit

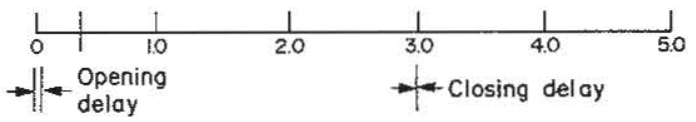

$+\quad 5 \times 10^{-3}$

FIG. 13. Ideal coil force function and coil current response of injector using step functions vs $C-D$ drive. 
Magnetic force will rise proportionally with this function. Valve actuation will not occur until a certain threshold field force has been reached.

Figure 13(a) depicts the desired magnetic force function. In Fig. 13(b) actual data on electromagnetic delay times for valve opening and closing are related with coil current.

A capacitor discharge $(C-D)$ injector driver circuit was developed which generates a current response closely approximating the ideal case. This utilizes a high current discharge of a capacitor to achieve very rapid magnetic field rise. Radical improvements in valve response time with decreased electrical power consumption have been achieved.

Tests on the Bosch injector using 75 psig hydrogen indicated flow development in $0.2 \mathrm{~ms}$ and flow cutoff in $0.5 \mathrm{~ms}$ using this system. Using step function actuation, these values were $1.5 \mathrm{~ms}$ and $2.0 \mathrm{~ms}$, respectively. The Bosch injector will not operate above 90 psig using step function actuation, but will operate at greater than 150 psig (limit of testing) using the $C-D$ driver circuit. Figure 13(c) depicts actual coil current response using this circuit with the Bosch injector.

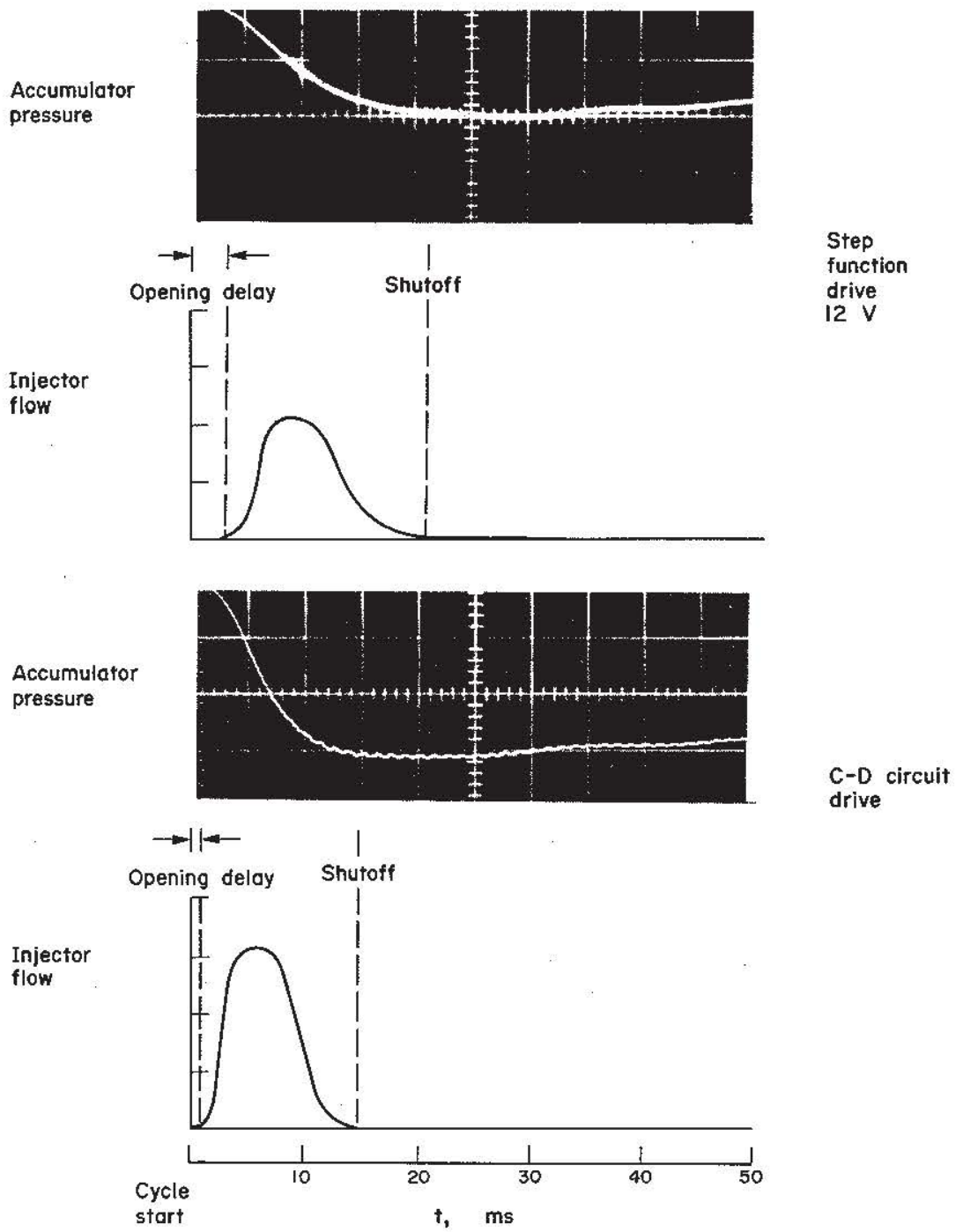

Flg. 14. Comparative flow responses of fluidamp injection, pulse deviation $=5 \mathrm{~ms}, p=30 \mathrm{psia}$. 
This driver circuit was employed in later testing of the Fluidamp injector and included in the final vehicle circuit design. Comparative Fluidamp injector responses with conventional and $C-D$ electronics are shown in Fig. 14.

\section{SYSTEM TESTING}

Engine tests were conducted using both direct and port injection system configurations. A premixed induction system was also evaluated, and baseline engine performance data using gasoline were taken. This work was directed towards testing and optimization of the experimental system hardware in actual application, and also provided a basis for evaluation of comparative system effectiveness in achieving the desired engine operational characteristics. Data presented here were generated using the Yamaha TX-650 test engine previously described.

\section{Baseline data setup}

For comparative performance evaluation, the TX-650 test engine was originally set up for operation on gasoline fuel, tuned to original factory specifications. At time of testing, the engine already had 5000 miles of actual operation logged. The power plant is normally fitted with dual constant velocity Mikuni-SU carburetors. Original exhaust equipment was retained.

A hydrogen carburetion (actually, gas-mixing) system was fabricated using two Impco type CA-50 propane carburetors modified for use with hydrogen. Modification was primarily aimed at achieving as rich a fuel-air mixture as possible with these units. Practically, an equivalence ratio of 0.55 was used during testing. A water induction system was fabricated using two POSA injection carburetors modified for variable water flow. These also served as the throttle bodies for air and fuel flow control. A separate system was used for each cylinder, but pressure equalization between intake ports was provided.

The stock ignition system of the TX-650 was retained. Static timing positions were used in most tests. Conventional spark plugs of a cold heat range were used, gapped to $1.5 \mathrm{~mm}$. It was necessary to locate the two ignition coils far apart to avoid electromagnetic cross induction observed early in testing.

\section{Port injection system}

An experimental electronically controlled manifold injection system was fabricated. This employed Type I injectors and a two cylinder version of the injection control electronics. Pressure to the injectors was maintained constant ( $40 \mathrm{psig}$ for most tests) and pulse duration variation was used to meter hydrogen delivery per injection. Maximum and minimum pulse durations (and thus $\phi$ ) were manually set to match the test conditions.

Although basically a quality governed system, air throttling was available to establish an acceptable idling condition.

Injection valves were located in positions adjacent to each intake port. The outlet nozzles terminated approximately $1 \mathrm{~cm}$ behind each intake valve with a clear spray path into the cylinder when the intake valve is open (see Fig. 15).

Water induction was available using the same system described for carbureted operation.

Triggering of injection cycle initiation was accomplished using a phototransistor-LED pair sensing system. Static injection timing was used, manually adjustable.

The original ignition system used in the carbureted hydrogen tests was retained.

\section{Direct injection system}

The installation for direct injection employed basically the same hardware described for port injection tests.

Injection into a pre-combustion chamber containing the spark plug was tested in several different configurations (Fig. 16). The concept behind this was to induce stratified charge formation in the cylinder which would allow the use of very low overall charge equivalence ratios to establish an engine idle condition without the need for air throttling. Thus, high efficiency at light loads, and very 


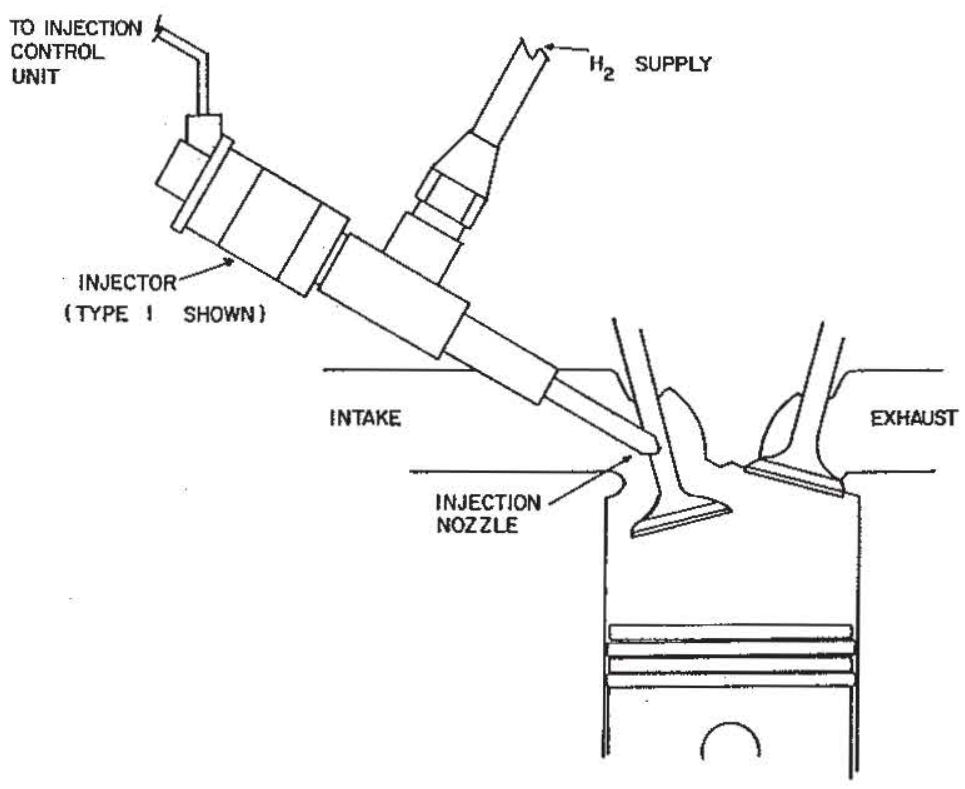

FIG. 15. Injector position for manifold injection.

low fuel consumption at idle would be possible due to elimination of intake vacuum pumping losses. Problems of erratic or lack of ignition were encountered with spark plug placement at the rear of the chamber. This was presumed to be the fault of insufficient air convection into the narrow throat chamber. A different igniter geometry was attempted, using a modified aircraft heater starter. The protruding tip of this igniter extended through the center of the chamber and the electrode exposed in the chamber throat area.

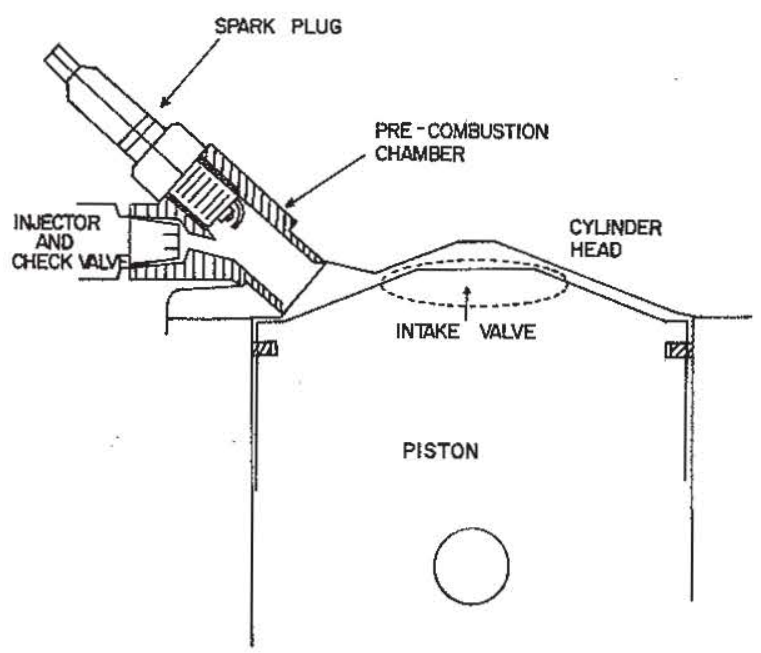

FIG. 16. Pre-combustion chamber cross section. 


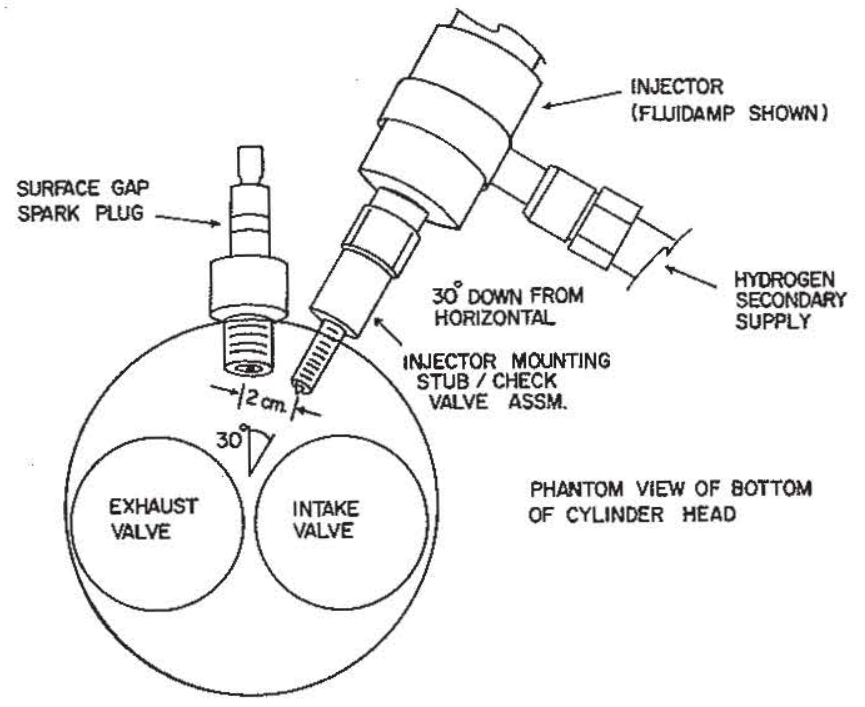

FIG. 17. Injection position for direct injection.

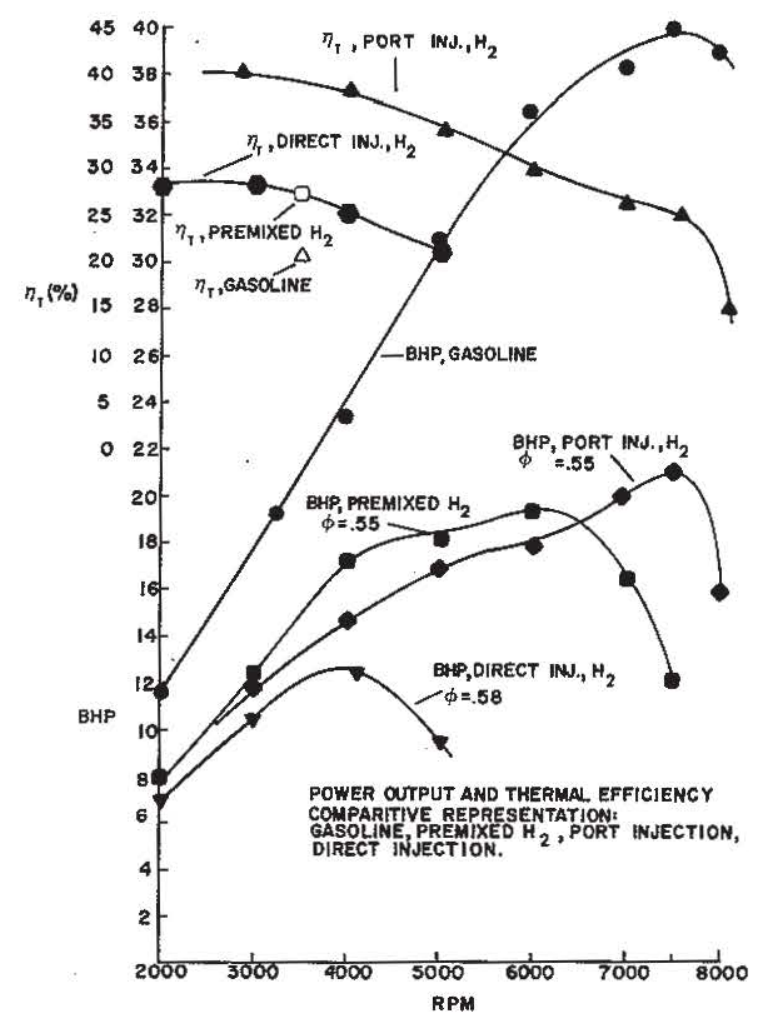

FIG. 18. Results of full throttle, variable RPM engine tests. 
Conventional ignition systems were incapable of ionizing the $4 \mathrm{~mm}$ electrode to wall gap under engine compression pressure. A high power, $1000 \mathrm{~mJ}$ pulse per ignition system was designed and fabricated to fire this igniter system. Problems of insufficient ignition were eliminated, but radical pre-ignition would occur after several seconds of engine operation. Clearly, the poor heat transfer properties of the extended electrode made it a high temperature site for pre-ignition. These problems forced abandonment of the pre-combustion chamber concept and an injection entry point approximately $2 \mathrm{~cm}$ from the normal spark plug position at an angle of $30^{\circ}$ from horizontal was used in later engine testing (Fig. 17).

These tests utilized the Fluidamp injector which is capable of withstanding combustion pressure. An additional check valve at the point of injection into the cylinder was employed later in testing to avoid a problem of metal fatigue in the poppet retaining springs of the Fluidamp injectors, due to the high gas temperatures present.

Polar gap spark plugs in conjunction with a high output Kettering ignition system were used. The spark plugs contained an internal air gap within the insulator shaft. This has been suggested as a means for improving the abruptness of discharge onset when using inductive ignition systems [31].

The injection control electronics used for port injection were retained, but modified by the addition of $C-D$ injector driver circuitry to improve the actuation of the Fluidamp injectors.

\section{Test apparatus}

A General Electric type TLC-50 dynamometer was employed, chain driven from the engine primary sprocket. Tests were performed in fifth (top) gear. Emissions were analyzed for total $\mathrm{NO}_{x}$ using a Thermo-electron model $10 \mathrm{~A}$ chemiluminescense analyzer. Exhaust oxygen was monitored with a Beckman F3M31A3B magnetic deflection type oxygen analyzer. A Beckman model 109 flame ionization detector was used to check for exhaust hydrocarbons from the engine lubricant. Exhaust port temperatures were recorded using Omega direct reading analog pyrometers. A Meriam model 50-MC2-4S laminar flow element was used to measure intake air flow rate. Hydrogen flow rate was inferred from pressure drop in a $\mathrm{K}$ type cylinder. Water induction rate was determined from burette water level drop.

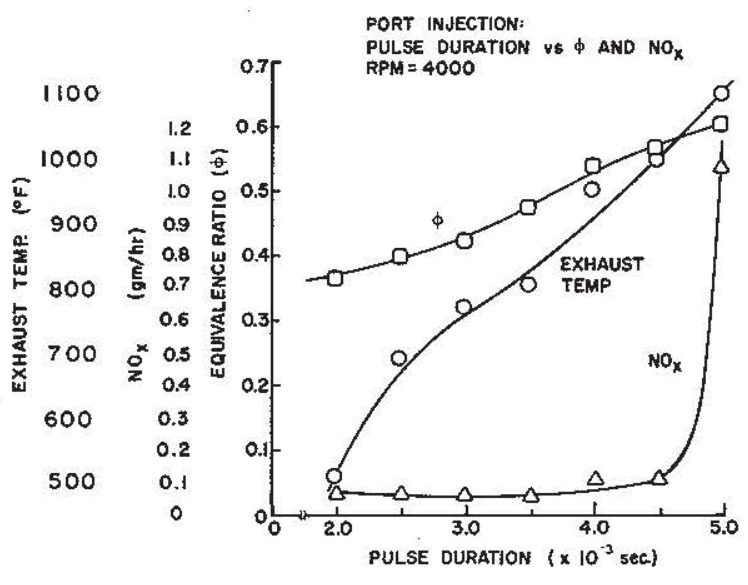

INJECTION PRESSURE $=40$ pSIg

INJECTION INITIATION AT $45^{\circ}$ ATDC

FIG. 19. Port $\mathrm{H}_{2}$ injection, constant rpm test results 
The results of full throttle, variable rpm tests on the four systems evaluated are illustrated in Fig. 18. All hydrogen aspiration systems were tested using approximately the same low rpm equivalence ratio. However, equivalence ratio was found to decrease significantly with $\mathrm{rpm}$ in the carbureted and direct injected systems. It is deduced that a flow starvation condition for both $\mathrm{H}_{2}$ and air causes the observed roll-off of the carbureted system above $6000 \mathrm{rpm}$. The port injection system, which employs an unrestricted air intake path, maintained a zero manifold vacuum, ideal flow condition through $7500 \mathrm{rpm}$, the maximum engine speed.

It was necessary to use water induction for suppression of random backfire over the entire rpm range with the carbureted system. At $3500 \mathrm{rpm}$, the water to hydrogen mass flow ratio required was 4.9. This approximately followed air flow, but was found to decrease at higher $\mathrm{rpm}$, a characteristic of the induction apparatus used. Engine operation above $6000 \mathrm{rpm}$ was quite rough, with sporadic backfire occurring regardless of water induction rate.

A $5 \mathrm{~ms}$ injection pulse duration was used in full power port injection tests. An injection initiation position of $45^{\circ}$ ATDC during intake was found to be optimum for backfire suppression. Advance of this timing position to earlier than TDC resulted in severe single charge backfiring at low rpm for any equivalence ratio. Under these conditions, an over-rich charge formed by accumulation of hydrogen behind the intake valve is inducted at the very beginning of the intake stroke. Pre-ignition due to combustion chamber surface effects and residual combustion products appears guaranteed. Substantial oil leakage into the combustion chamber was evident from significant exhaust hydrocarbon figures, indicating a plentiful source of potential combustion nuclei available. It may also be possible that the accumulated hydrogen charge behind the valve was igniting by combustion product leakage past the closed valve. Injection initiation positions later than $30^{\circ}$, but prior to $60^{\circ}$, ATDC resulted in backfire-free performance up to $5000 \mathrm{rpm}$ under all load conditions. This appears to verify the effectiveness of late fuel delivery in eliminating intake pre-ignition. The $5 \mathrm{~ms}$ injection duration used begins to overlap its allowed duration in the intake stroke above $4500 \mathrm{rpm}$. Residual fuel may be accumulated behind the intake valve at engine speeds above this. Roughness of engine operation above $5000 \mathrm{rpm}$ was observed, presumably due to this effect. For the full power tests conducted using $\phi=0.55$, water induction was employed above $5000 \mathrm{rpm}$ to circumvent this problem. The required water/hydrogen mass ratio at $6000 \mathrm{rpm}$ was 10.8 .

Full power tests on the direct injection system demonstrated the engine speed limitations imposed by longer injector actuation times. Injection cycle initiation at $90^{\circ} \mathrm{ATDC}$ was used for these tests to maximize allowable injection duration. The Fluidamp injectors require $10 \mathrm{~ms} /$ injection cycle when driven by a $5 \mathrm{~ms}$ pulse duration. This is acceptable for the intended vehicle system. Flow limitation begins above $3000 \mathrm{rpm}$ for the $30 \mathrm{psig}$ fuel pressure used. Power appears to reach a peak between 3000 and $4000 \mathrm{rpm}$. The backfire condition was not observed.

Comparisons of equivalence ratio, $\mathrm{NO}_{x}$ emissions and exhaust temperature with pulse duration were generated in constant rpm testing of both injection geometries. The manifold injection tests yielded the data of Fig. 19. Flow limitations of the Type I injectors prevented operation richer than $\phi=0.60 . \mathrm{NO}_{x}$ emissions follow prediction with trivial $\mathrm{NO}_{x}$ below $\phi=0.55$ and an exponential rise beginning at about $\phi=0.60$.

A significant discrepancy between $\phi$ figures determined from measurement of intake air and hydrogen vs $\phi$ determined from analysis of exhaust oxygen content was observed for the direct injection system. Figure 20 indicates this difference plotted vs injection pulse duration. $\phi_{\text {effectivc }}$ is a pseudo-equivalence ratio determined with an assumption of complete combustion from the exhaust oxygen content. Unusually high $\mathrm{NO}_{x}$ production was observed and is seen to follow the intake $\phi$ exponentially, determined from intake product flow measurements. These observations indicated that incomplete combustion was occurring. High $\mathrm{NO}_{x}$ figures may be the result of stratified charge formation and combustion occurring in local high $\phi$ regions. Injection initiation occurred at BDC for these tests. A retarding of the ignition timing was required for pulse durations greater than $5.0 \mathrm{~ms}$ to avoid combustion knock and unstable torque.

The relationship between combustion completeness and engine rpm is illustrated in Fig. 21. Turbulence inducing swirl fins were fabricated into the engine intake ports in an effort to improve mixing. The engine was operated on one cylinder, the motoring loss of the other cylinder providing a light load, approximately linear with rpm. Injection initiation at $120^{\circ}$ ATDC was used for this test, 


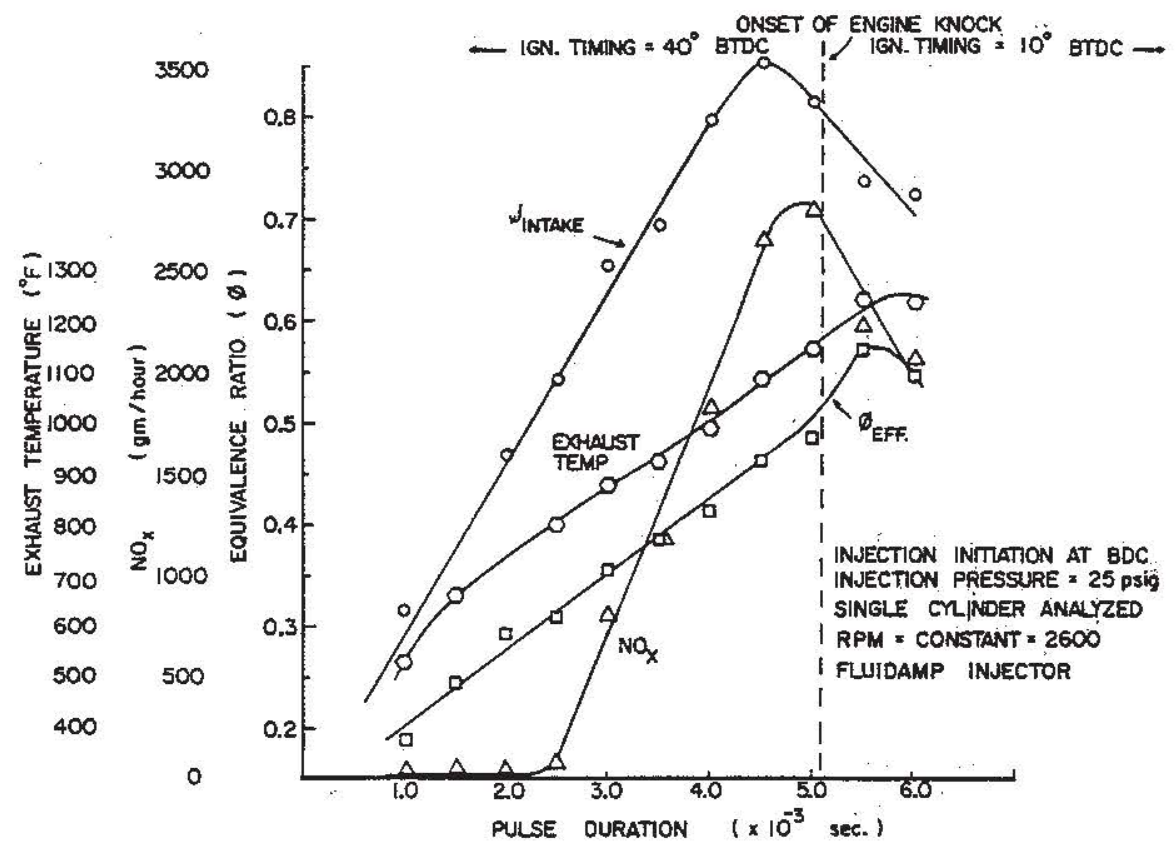

FIG. 20. Direct $\mathrm{H}_{2}$ injection, constant rpm test results.

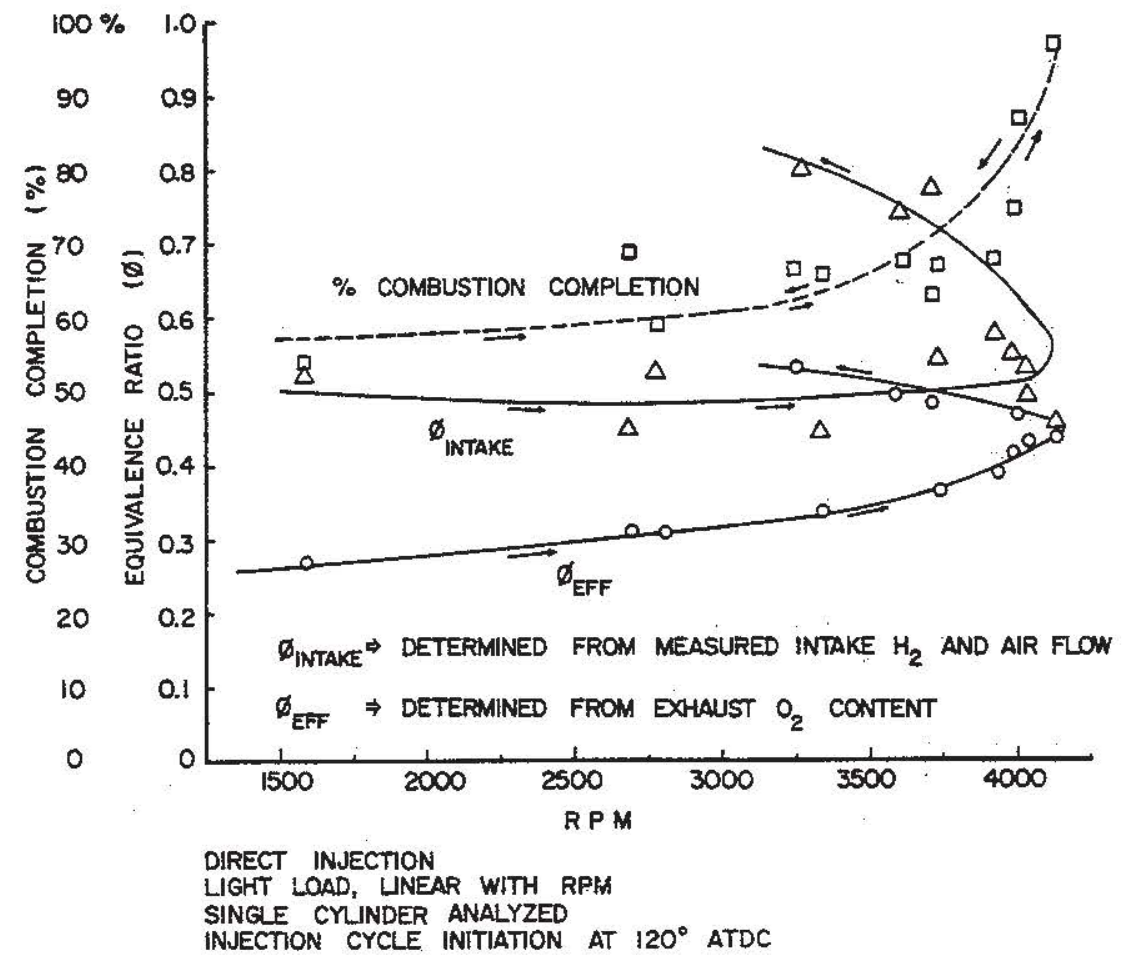

FIG. 21. Direct injection: combustion completion vs engine rpm. 
which results in the majority of fuel delivery between BDC and $90^{\circ}$ BTDC at $4000 \mathrm{rpm}$. Completeness of combustion was seen to improve with rpm from a low of about $55 \%$ at $1500 \mathrm{rpm}$ to $97 \%$ at 4150 rpm. This appears to underscore the need for a high degree of in-cylinder turbulence to achieve adequate combustion completeness in direct cylinder charge formation.

Highest thermal efficiency $\left(\eta_{t}\right)$ was achieved with the port injection system, $40 \%$ at low rpm, decreasing with increasing $\mathrm{rpm}$ (Fig. 18). The lower $\eta_{t}$ values of the direct injection system were explained by the incomplete combustion observed. Efficiency of the premixed charge system was $27 \%$ at $3500 \mathrm{rpm}$. A comparison figure for gasoline was $21 \%$ at $3500 \mathrm{rpm}$.

A persistent problem of undesired injection triggering due to ignition system electrostatic noise was encountered due to the close proximity of the trigger unit to the right cylinder spark plug. This required extensive shielding of the trigger unit, interface cable and the injection control unit itself.

Failure of the Fluidamp injector-check valve assembly occurred due to heat effects on the check valve moving part and the poppet retainer spring of the injector. Design refinement for improved heat transfer from these parts is indicated.

A simulated life cycle test performed on a Type I injector over 25 million cycles indicated most probable failure due to wear of moving part surfaces. This is enhanced by heat effects in direct injection applications. The use of high temperature abrasion resistant coatings may be desirable for moving part mating surfaces in a production design.

\section{CONCLUSIONS}

Delayed fuel delivery, using a timed fuel injection technique either at the intake port or directly into the cylinder, is effective in circumventing the problem of backfire into the intake manifold.

Electronic control of fuel injection is feasible and may easily provide the control flexibility necessary for optimum overall engine performance.

An electronically actuated injection valve with sufficient flow rate and actuation speed can be fabricated and applied in either port or direct cylinder hydrogen injection systems.

Direct cylinder injection is susceptible to incomplete combustion and high $\mathrm{NO}_{x}$ emissions due to heterogeneous charge formation. Mixing improves with rpm due to increased turbulence. Possible improvements in volumetric efficiency by compression stroke injection are offset by thermal efficiency loss due to incomplete combustion.

Port injection requires less sophisticated injection valves and avoids the problems associated with incomplete mixing in direct injection. At the present level of development, port injection appears more feasible.

Acknowledgement-The authors gratefully acknowledge the assistance of colleagues at UCLA, most notably Professor A. Z. Ullman, and the financial support of the U.S. Postal Service.

\section{REFERENCES}

1. J. G. Finegold \& W. D. VAN Vorst, Hydrogen Engine Technology, Proc. $X V^{e}$ Congress International F.I.S.I.T.A., Societe des Ingenieurs de l'Automobile, Paris, France (May 1974).

2. W. D. VAN Vorst \& J. G. Finegold, Automotive Hydrogen Engines and Onboard Storage Methods, Proc. Hydrogen Energy Fundamental Symp., Miami Beach, Florida (March 1975).

3. E. F. OBERT, Internal Combustion Engines, International Textbook Co., Scranton, Pennsylvania (1968).

4. R. A. ERREN \& W. H. CAMPBELL, Hydrogen: a commercial fuel for internal combustion engines and other purposes, J. Inst. Fuel 6, 277-290 (1933).

5. E. P. A. HeINZE, The Erren hydrogen engine, Engineering pp. 607-608, (November 1932).

6. M. OEHMichen, Wasserstoff als Mortoreibmittel, Verein Deutsche Ingenieur, Deutsche Kraftfahrtforshung, Heft 68, 1942, (as noted in [18]).

7. R. G. Murray, R. J. Schoeppel \& C. L. Gray, The Hydrogen Engine in Perspective, SAE 729216, Proc. 7th Int. Energy Conv. Engr. Conf. (IECEC), Am. Chem. Soc., Washington, D.C. (1972).

8. K. SaGa \& S. Furuhama, Performance and Emission Control in Stratified Charge Hydrogen Fueled Engines, Musashi Institute of Technology, Tokyo, Japan (1976).

9. W. J. MCLeAN, P. C. T. DE BoER, H. S. Homan \& J. J. FAGELSON, Hydrogen as a Reciprocating Engine Fuel, Proc. Future Automotive Fuelds Symposium, 5-6 October, 1975.

10. M. R. SwaIn \& R. R. AdT, The Hydrogen-Air Fueled Automobile, Proc. Inter-society Energy Conversion Engineering Conf. (IECEC), San Diego, California (1972). 
11. A. WINKLER \& R. SuTron, Bendix electronic fuel-injection system, SAE Trans. 65 (1957).

12. G. BaumanN, Bosch Electronically Controlled Gasoline Injection System for Spark Ignited Engines, Robert Bosch G.m.b.H., Stuttgart, W. Germany (1967).

13. Tractor and Mechanical Publications, The Petrol Fuel Injection Book for Automobiles, P.I. 1972, Interauto Co., Ltd, Middlesex, England (1972).

14. J. H. ScHLAG, Automatic Computer Controlled Calibration of EFI Control Units, SAE Trans., 760243, 1976.

15. Society of Automotive Engineers, First Digital Microprocessor Goes to Toronado, Automobile Engineering 84, (10) 49 (October 1976).

16. R. O. KING, The Explosion of Mixtures of Combustible Gases with Air by Nuclear Drops of Water and Other Nuclei and X-Rays. Canadian Air Ministry Official Report (1950).

17. A. S. Sokolik, Self-Ignition, Flame and Detonation in gases, (translated by N. Kaner, 1963) Akademiya Nauk SSSR, Institut Khimicheskoi Fiziki, Izdatel'stvo Akademii Nauk SSSR, Moskva. 1960. Ch. VII.

18. P. C. T. DE BoeR, W. J. MCLean \& H. S. Homan, Performance and Emissions of Hydrogen Fuel Internal Combustion Engines, presented at Hydrogen Fundamentals Symp., Miami, Florida (1975).

19. R. O. King, I. J. DuRAND, B. D. Wood \& A. B. AllaN, The Oxidation, Ignition, and Detonation of Fuel Vapors and Gases, XIV. Can. J. Res. 28, Sec. F. (1950).

20. R. L. Woolley \& D. L. HenRiksen, Water induction in hydrogen powered I.C. engines, Int. J. Hydrogen Energy 1, 401-412 (1977).

21. A. LA Fleur, Ternary and Quaternary explosion regions and La Chatelier's formula, Rec. Travoux Chim. Pays Bas 56, 442-473 (1937).

22. H. F. CoWARD \& G. W. Jones, Limits of Flammability of Gases and Vapors, Bulletin 503, U.S. Bureau of Mines, 15-24 (1952).

23. P. EITNER, Explosion limits of flammable gases and vapors, Habilitations-Schriff, München, Jour. Gasbel. 45 (1902)

24. J. BretoN, Ann. Office Natl. Combustibles Liquides, 11487, Theses Faculté des Sciences, Univ. Nancy (1936).

25. Z. WendlandT, Physik Chem. 110, 637 (1924).

26. B. Lewis \& G. von ElBE, Combustion, Flames and Explosions of Gases. Academic Press, New York (1961).

27. C. A. MaCCARLEY, Development of a Sodium Borohydride $H$ drogen Fuel Storage System for Automotive Applications, Proc. Symp. Alternative Fuels, AIAA, Santa Maria, California 1976.

28. H. YU, Fuel distribution studies, SAE Trans. 71, 596-613 (1963) (as noted in [3]).

29. C. A. MACCARLEY, Electronic Fuel Injection Techniques for Hydrogen Fueled I.C. Engines, M.S. Thesis in Engineering, University of California, Los Angeles (1978).

30. F. E. LxNCH, Denver Research Institute, Personal correspondence, (September 1977).

31. W. DreXt, H. Holzt \& M. Gutmann, Characteristics of a Single Cylinder Hydrogen-Fueled 1.C. Engine Using various Mixture Formation Methods, Daimler-Benz AG Central Research, 7 Stuttgart 60, Germany (1976). 